\title{
Bioenergia em Moçambique: tecnologias de produção, uso e aspetos sustentáveis
}

\author{
António Gonçalves Fortes ${ }^{1}$ \\ Baltazar Raimundo ${ }^{2}$
}

\begin{abstract}
RESUMO
Face aos problemas socioambientais e econômicos resultantes do uso dos combustíveis fósseis, Moçambique vem implementado diversos projetos de inclusão das energias renováveis (ER) na matriz energética nacional. Uma alternativa promissora é o uso da bioenergia, com vista a explorar seu potencial para produção sustentável de energia. Nessa perspectiva, este artigo objetiva realizar a caracterização do setor de bioenergia em Moçambique, através das tecnologias usadas na conversão, o contexto legal e os aspetos sustentáveis na produção e utilização desta fonte. Os resultados mostram que a biomassa (sólida, liquida e gasosa) pode ser utilizada diretamente para geração de calor e/ou eletricidade. A biomassa lenhosa é a mais usada pela população moçambicana para fins domésticos, e casualmente, para fins comercial e industrial. Concluir que, para o atual cenário nacional, a inclusão da biomassa derivada de rejeitos urbanos e industriais pode resolver, em simultâneo, o problema energético e de gestão de resíduos. É sustentável a relação entre a produção de alimento - geração de energia - preservação do meio ambiente. E o uso de tecnologias eficientes na geração dos biocombustíveis reduz os impactos ambientais e a dependência dos combustíveis fósseis, para além de promover os serviços de maior qualidade, contribuir para o aumento da eficiência de conversão e na sustentabilidade energética, especialmente na área rural.
\end{abstract}

Palavras chaves: bioenergia; fonte alternativa; tecnologias de produção; sustentabilidade.

\section{Bioenergy in Mozambique: production technologies, use and sustainable aspects}

\begin{abstract}
In view of the socio-environmental and economic problems resulting from the use of fossil fuels, Mozambique has implemented several projects to include renewable energies (RE) in the national energy matrix. A promising alternative is the use of bioenergy, with a view to exploring its potential for sustainable energy production. In this perspective, this article aims to characterize the bioenergy sector in Mozambique, through the technologies used in the conversion, the legal context and the sustainable aspects in the production and use of this source. The results show that biomass (solid, liquid and gaseous) can be used directly to generate heat and/or electricity. Woody biomass is the most used by the Mozambican population for domestic purposes, and casually, for commercial and industrial purposes. To conclude that, for the current national scenario, the inclusion of biomass derived from urban and industrial waste can simultaneously solve the energy and waste management problem. The relationship between food production - energy generation - preservation of the environment is sustainable. And the use of efficient technologies in generation of biofuels reduces environmental impacts and dependence on fossil fuels, in addition to promoting higher quality services, contributing to increasing conversion efficiency and energy sustainability, especially in rural areas.
\end{abstract}

Keywords: bioenergy; alternative source; production technologies; sustainability.

\section{INTRODUÇÃO}

Os problemas socioambientais e econômicos resultantes do uso excessivo dos combustíveis fósseis favorecem a busca pelas fontes de ER. Uma das opções práticas e

\footnotetext{
${ }^{1}$ Mestre em Eng. Geológica. Docente da Faculdade de Ciências Naturais, Estatística e Matemática, Extensão de Nampula, Campus de Napipine. Universidade Rovuma, Moçambique. antoniogoncalves.fortes@ yahoo.com

${ }^{2}$ Mestrando em Engenharia de Gestão e Energia e docente da Faculdade de Ciências Naturais, Estatística e Matemática. Extensão de Montepuez, Campus de Nkorripo. Universidade Rovuma, Moçambique.
} 
sustentáveis adotadas é o uso de biomassa. A quantidade estimada de biomassa existente na Terra é de cerca de 1,8 trilhão de toneladas, o que constitui $10 \%$ da oferta de energia primária (SOUZA et al., 2015a). Uma das grandes particularidades e vantagens da biomassa é a versatilidade na utilização, como combustível sólido, líquido e gasoso, o que a torna única e adequada para diversas aplicações.

As ER desempenham um papel importante na matriz energética moçambicana. Uma parte substancial da procura de energia, cerca de 80\% (GUEIFÃO et al., 2013; RAPOSO et al., 2015) é satisfeita através da biomassa tradicional, usada para atender as necessidades energéticas domésticas, embora alguns empreendimentos comerciais e industriais também usam a biomassa para gerar calor (BROUWER; FALCAO, 2004).

Entre as bioenergias mais aproveitadas, estão a biomassa florestal (natural ou resíduos da atividade florestal), de explorações agrícolas (dedicada ou resíduos agrícolas) e os resíduos sólidos urbanos (RSU) e industriais (RSI) (ALER, 2017). A superfície florestal do País é de 34 milhões de $h a$, cerca de $43 \%$ da área total (AQUINO et al., 2018), o que constitui uma oportunidade para a obtenção de benefícios através da gestão adequada e o consequente desenvolvimento socioeconómico (NUBE et al., 2016).

Como referência, Moçambique é um dos dez maiores produtores de carvão vegetal do mundo. Estima-se que os resíduos da atividade florestal a nível nacional poderiam gerar 750 GWh de energia (ALER, 2017). Além disso, estima-se que é possível produzir 3,1 milhões de barris equivalentes de petróleo por dia de biocombustíveis sem afetar a produção agrícola ou pôr em risco a biodiversidade (GUEIFÃO et al., 2013; VAZ et al., 2011)

A produção de biocombustíveis no País iniciou-se em 2007, e pela dinâmica do setor, têm ocorrido mudanças nas estruturas produtivas, concorrendo para a substituição da matriz produtiva local, alterando as produções familiares, elevando as densidades técnicas e as formas de usos e aproveitamento da terra (LANGA; SOUZA; HESPANHOL, 2013). A demanda mundial por biocombustíveis deverá crescer a taxas elevadas, motivada pela conscientização da necessidade de deter o processo de aquecimento global, bem como pela preocupação de uma possível escassez de petróleo (CARVALHO; FERREIRA, 2014).

A bioenergia desenvolvida com conhecimento e implementada considerando as necessidades locais, pode ajudar a aumentar a resiliência da oferta de alimentos, diminuir a poluição e preservar a biodiversidade, melhorar a saúde humana e outros seres vivos, recuperar terras degradadas, mitigar os efeitos das mudanças climáticas e propiciar oportunidades econômicas e de negócios (FERREIRA, 2015; SOUZA et al., 2015a). 
Nesta ótica, este artigo objetiva realizar a caracterização do setor de bioenergia - biogás, etanol, biodiesel, lenha, carvão vegetal e biomassa florestal - em Moçambique, indicando as tecnologias de conversão de energia, o contexto legal e os aspetos sustentáveis na cadeia de produção e uso das bioenergias, especialmente nas zonas rurais e áreas suburbanas.

O presente artigo está dividido em cinco partes, sendo elas: a introdução e contexto, o referencial teórico, a metodologia, os resultados e análises, e as considerações finais.

\section{REFERENCIAL TEÓRICO}

\subsection{Recursos de biomassas como fonte das bioenergias}

No contexto energético, o termo biomassa refere-se ao material biológico, não fóssil, de origem vegetal, animal ou microbiana, que pode ser convertido em energia, designada de bioenergia (PROTÁSIO et al., 2012). Este material inclui a matéria vegetal gerada pela fotossíntese e subprodutos, como resíduos agrícolas, agroindustriais florestal, excrementos de animais e a fração biodegradável de resíduos urbanos e industriais.

A biomassa pode ser classificada em dois grandes grupos: (i) biomassa tradicional, composta essencialmente pela lenha e resíduos naturais, e (ii) biomassa moderna, produzida a partir de processos tecnológicos avançados e eficientes, tais como biodiesel, biogás, briquetes e pellets, cogeração e os cultivos dedicados de espécies em florestas plantadas e a cana-deaçúcar (GOLDEMBERG, 2009; MARAFON et al., 2016; RAPOSO et al., 2015).

Existem vários processos de conversão de biomassa em energia, porém os dois principais são: decomposição termoquímica (combustão, pirólise e gaseificação) e a conversão bioquímica (digestão anaeróbia e a fermentação). Para a escolha do processo consideram-se vários fatores, como o tipo e quantidade de biomassa disponível, qualidade do combustível e custo, normas ambientais, políticas públicas e questões socioeconômicas (GOLDEMBERG, 2009; PITOL-FILHO, 2011). A tecnologia mais usada no País é a decomposição termoquímica.

A renovação na biomassa se dá através do ciclo do carbono (Fig. 1). A decomposição ou a queima da matéria orgânica e seus derivados provoca a liberação de dióxido de carbono $\left(\mathrm{CO}_{2}\right)$ na atmosfera. As plantas, através da fotossíntese, transformam o $\mathrm{CO}_{2}$ e água nos hidratos de carbono, que compõe sua massa viva, liberando oxigênio. Assim, a utilização sustentável da biomassa não altera a composição média da atmosfera ao longo do tempo. 
Figura 1. Etapas do ciclo de carbono.

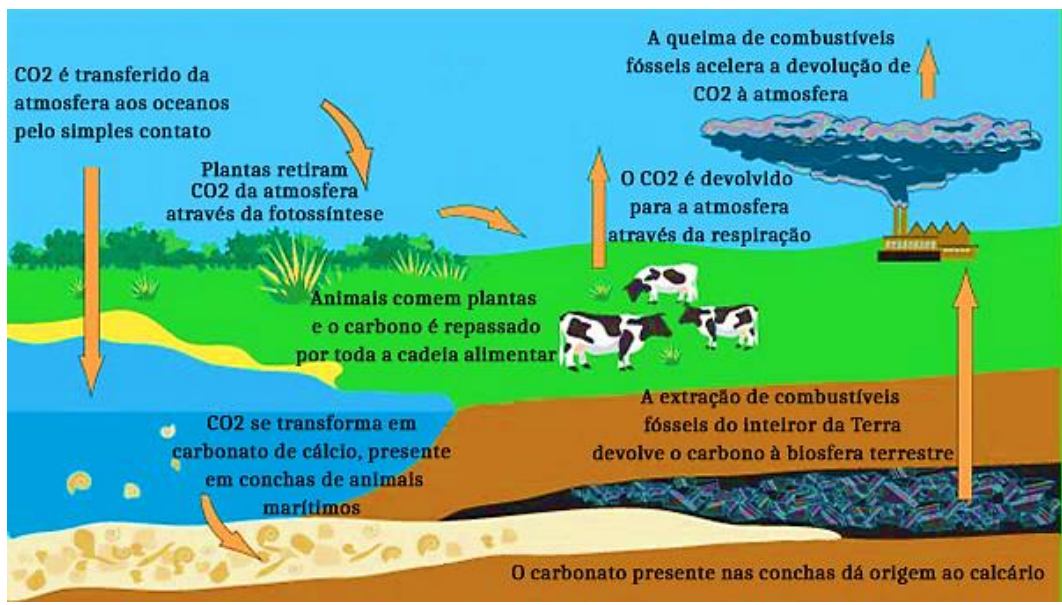

Fonte: https://www.significados.com.br/ciclo-do-carbono/> Acesso em 03/03/2020

Altos teores de carbono e hidrogênio e baixos teores de oxigênio são desejáveis quando a biomassa é utilizada como fonte de energia devido às correlações existentes entre esses parâmetros e o poder calorífico (PROTÁSIO et al., 2012). E biomassa com alto teor de carbono fixo e baixo teor de materiais voláteis tendem a se queimar mais devagar (BRAND et al., 2014).

Através de diversos processos de conversão (Fig. 2), é possível obter biocombustíveis sólidos, líquidos e gasosos que, por sua vez, podem gerar energia térmica, mecânica ou elétrica.

Figura 2 - Fontes de biomassa e seus processos de conversão.

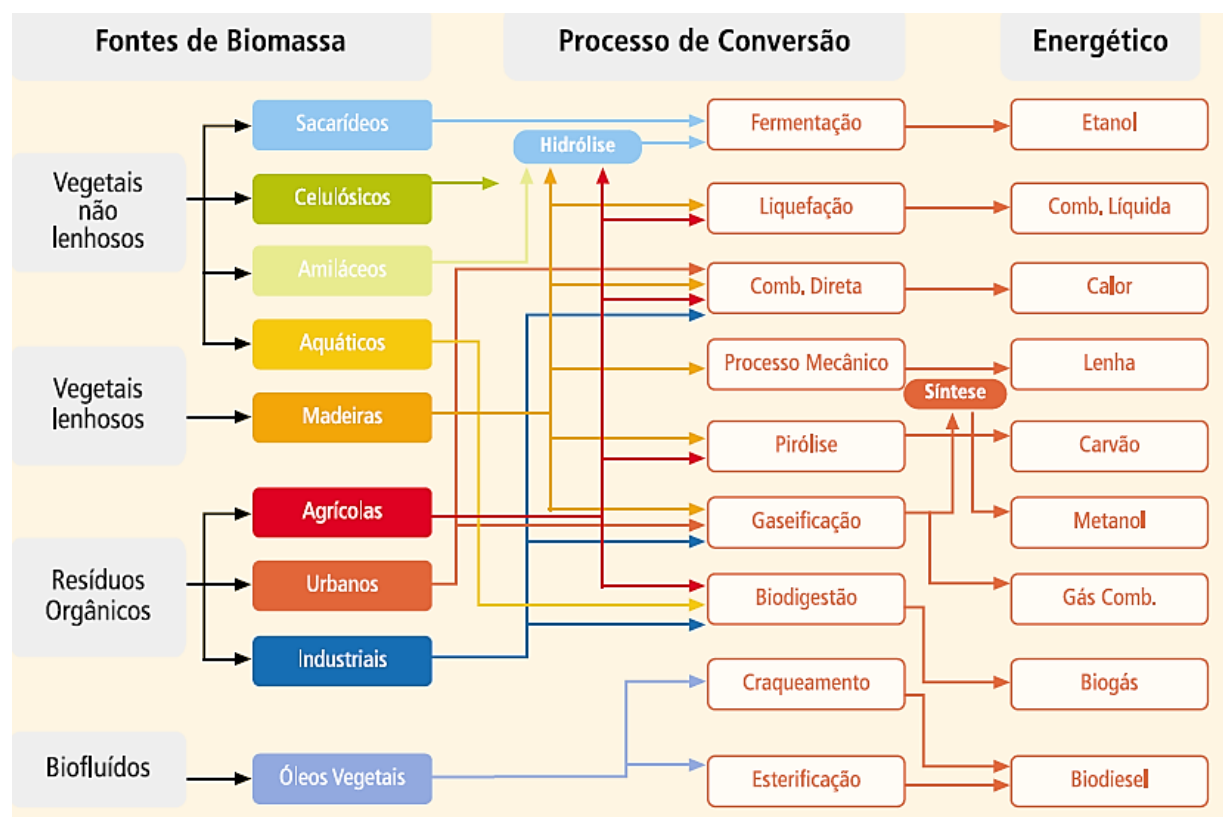

Fonte: http://www.iee.usp.br/gbio/?q=livro/fontes-de-biomassa $>$. Acesso em 06/03/2020 


\subsection{Processamento dos biocombustíveis em Moçambique}

O termo biocombustível aplica-se a todos os elementos orgânicos capazes de gerar combustão. Nesta perspectiva, abrange os combustíveis sólidos, líquidos, gasosos e gelatinosos. No trabalho, classificou-se em biomassa florestal, biomassa lenhosa, biogás, etanol e biodiesel.

\subsubsection{Biomassa Florestal}

Moçambique é um dos poucos países na região da África Austral que ainda mantém uma proporção considerável da sua área coberta com florestas naturais e matas remanescentes, principalmente do tipo miombo, que cobre 2/3 da superfície do País (NUBE et al., 2016).

A biomassa florestal utilizada na geração de energia elétrica ou térmica, pode ser procedente de resíduos da exploração convencional da madeira ou de árvores das plantações dedicadas à exploração florestal para fins energéticos. A utilização desta biomassa depende das características termoquímicas, como a composição química, granulação, densidade, carbono fixo, materiais voláteis e os teores de cinza, de umidade e de lignina, que definem a eficiência, o poder calorífico e o valor comercial.

No País, a biomassa florestal é usada por combustão direta. Porém, os resíduos agroflorestais in natura possuem baixa eficiência energética, devido à baixa densidade, alta umidade e baixo poder calorífico. A vantagem de uso dos briquetes e pellets (Fig. 3) é o aumento da densidade energética, resistência e poder calorífico (RAPOSO et al., 2015).

Figura 3 - Briquetes com diâmetro entre 50-100 mm e comprimento maior que $100 \mathrm{~mm}$, e pellets com diâmetro entre 6-16 mm e comprimento menor que $30 \mathrm{~mm}$.

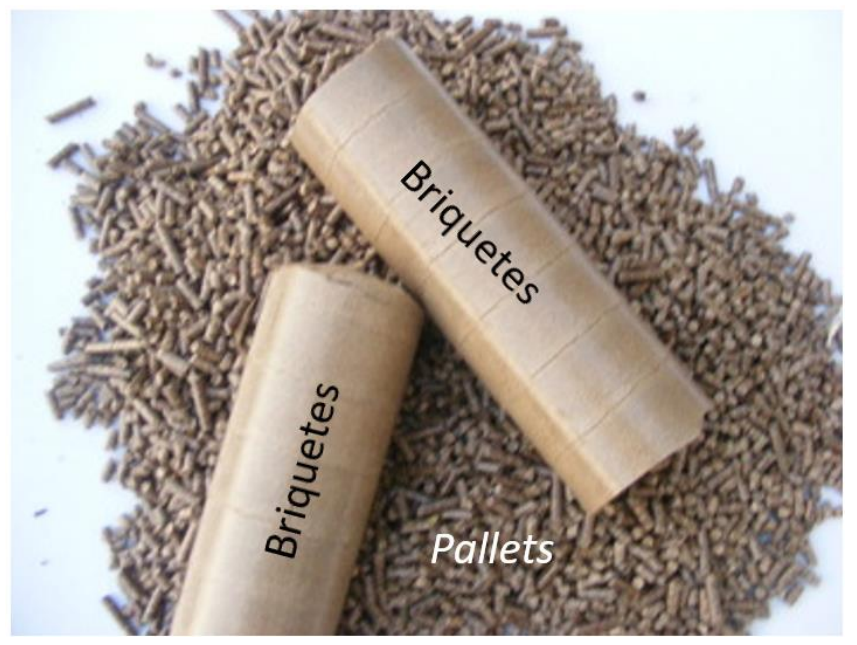

Fonte: http://www.lippel.com.br/br/briquetagem-e-peletizacao.html > acesso em 02/02/2020 


\title{
2.2.2. Biomassa lenhosa
}

A lenha e carvão são essenciais para suprir as necessidades energéticas das famílias, com a biomassa lenhosa representando $80 \%$ do consumo total de energia em Moçambique (AQUINO et al., 2018). O inventario florestal apontou um total de 1,6 mil milhões de toneladas de biomassa lenhosa (ALER, 2017) de origem natural disponível em Moçambique (tabela 1), concentrada nas províncias de Zambézia e Niassa.

A causa da elevada procura por lenha e carvão está associada ao crescimento econômico e populacional, falta de alternativas de energia doméstica, dúvidas nas políticas institucionais e na cadeia de transporte e distribuição (ECUSEB, 2013). Apesar dos esforços para eletrificação e disponibilização de gás de cozinha, há poucos agregados familiares que adotaram estas alternativas, sendo que, apesar destas usarem hidroeletricidade para iluminação, continuam a cozinhar com lenha e carvão (SITOE; SALOMÃO; WERTZ-KANOUNNIKOFF, 2012).

\begin{abstract}
Existem diferenças na aquisição e consumo de combustíveis lenhosos: (i) na zona rural, a lenha é a forma dominante de energia. Ela é obtida principalmente de ramos e árvores secas naturalmente ou derrubados para abrir machambas. A intensidade de exploração de lenha para uso na zona rural é baixa e corresponde à densidade populacional baixa, típica de povoados. Nas zonas urbanas, o carvão é a forma dominante de combustível lenhoso ao nível doméstico enquanto as indústrias e as grandes cozinhas utilizam a lenha. A exploração de lenha e fabrico de carvão para consumo urbano é feita de modo intensivo e com o abate de árvores de forma pouco seletiva em relação a espécie e tamanho (SITOE et al., 2012: p. 9).
\end{abstract}

Em geral, três cenários de fornecimento de energia de biomassa lenhosa podem ocorrer no País (tabela 1): (i) excedente, o caso atual em Cabo Delgado, Zambézia, Manica e Niassa; (ii) equilíbrio aproximado entre oferta e demanda, como no caso de Gaza, Inhambane, Sofala e Tete; e (iii) escassez, como no caso de Maputo e Nampula. As soluções propostas para cada região dependerão o saldo de abastecimento (VISSER, 2012, p. 1).

Tabela 1. Recursos de biomassa lenhosa disponível no País.

\begin{tabular}{l|l|c|c}
\multirow{2}{*}{ Região } & \multicolumn{1}{|c|}{ Província } & População* (habitantes) & Total biomassa lenhosa (1.000 t) \\
\hline \multirow{3}{*}{ Norte } & Niassa & 1865976 & 308447 \\
\cline { 2 - 4 } & Cabo Delgado & 2333278 & 178505 \\
\cline { 2 - 4 } & Nampula & 6102867 & 169033 \\
\hline \multirow{3}{*}{ Centro } & Zambézia & 3110787 & 248529 \\
\cline { 2 - 4 } & Tete & 2764169 & 169455 \\
\cline { 2 - 4 } & Manica & 1911237 & 144755 \\
\cline { 2 - 4 } & Sofala & 2221803 & 126496
\end{tabular}




\begin{tabular}{l|l|c|c}
\multirow{4}{*}{ Sul } & Inhambane & 1304820 & 125461 \\
\cline { 2 - 4 } & Gaza & 1236284 & 112708 \\
\cline { 2 - 4 } & Maputo & 1225489 & 31464 \\
\cline { 2 - 4 } & Maputo cidade & 1111638 & 238 \\
\hline Total & Moçambique & $\mathbf{2 8 ~ 8 6 1 ~ 8 6 3}$ & $\mathbf{1 . 6 1 5 . 0 9 1}$
\end{tabular}

Fonte: (ALER, 2017, p. 123). * Dados extraídos do: http://www.ine.gov.mz/ (22/03/2020).

\subsubsection{Biogás: Resíduos Sólidos Urbanos (RSU)}

O biogás pode ser obtido através de processos naturais (ação de microrganismos bacteriológicos) e em material orgânico ou artificial (em biodigestores anaeróbicos).

O biogás possui conteúdo energético semelhante ao do gás natural, sendo constituído pela mistura de hidrocarbonetos com $\mathrm{CO}_{2}$ e gás metano $\left(\mathrm{CH}_{4}\right)$. $\mathrm{O}$ biogás pode ser usado para a geração de energias elétrica, térmica e mecânica. A vantagem do biogás em relação ao gás natural é o fato de ser renovável e produzido em todos locais onde haja disponibilidade de biomassa, apesar de ter um baixo poder calorifico relativo, umidade e sulfeto de hidrogênio $\left(\mathrm{H}_{2} \mathrm{~S}\right)$ na sua composição (PEREIRA; NETO, 2011).

O aproveitamento energético dos RSU é realizado através da sua queima direta para geração de energia elétrica ou através da deposição em aterros sanitários para a produção de biogás, podendo ainda ser usado diretamente ou queimado para geração de energia elétrica. No País, o potencial estimado é de 63 MW (ALER, 2017; GUEIFÃO et al., 2013).

Existe um estudo de viabilidade realizado em 2015, pela empresa GreenLight e o Instituto Técnico Real KTH da Suécia, no Município de Quelimane, para aproveitar os RSU para gerar eletricidade e biogás de cozinha, em função das características do material orgânico nos RSU, tecnologias de conversão de energia e modelos de gestão dos RSU.

\subsubsection{Etanol: Cogeração da indústria açucareira}

O etanol ou álcool etílico é um biocombustível produzido a partir da fermentação de amido e de outros açúcares. Pode ser produzida por culturas amiláceas (milho), cana-de-açúcar, beterraba e mapira, mas no País, há inclusão da mandioca, devido ao seu baixo custo de produção. Um dos pontos fortes para a produção do álcool etílico é a possibilidade de substituir a gasolina e consequentemente, redução da importação e dependência do petróleo. 
O etanol é considerado um combustível renovável e sustentável, pois emite baixa quantidade de gases poluentes em comparação com os combustíveis fósseis. Na sua produção, grande parte do $\mathrm{CO}_{2}$ produzido e libertado na atmosfera é absorvido pelas plantas, pela fotossíntese, tornando-se um dos combustíveis mais viáveis ecologicamente.

A prensagem da cana-de-açúcar origina um produto líquido: melaço, rico em açúcar e o bagaço, um resíduo sólido composto basicamente por hemicelulose e celulose (PITOL-FILHO, 2011). Segundo Cardona et al. (2010) uma tonelada de cana-de-açúcar gera $280 \mathrm{~kg}$ de bagaço, sendo constituído por lignina (20-30\%), celulose (40-45\%), hemicelulose (30-35\%) e cinzas (em torno de 2\%). Tradicionalmente, o bagaço é usado para produzir energia em cogeração, fornecendo vapor para o processo fabril e geração de energia elétrica. O potencial estimado desta fonte de energia no País é de 832 MW (ALER, 2017).

Há uma destilaria de etanol em operação atualmente em Moçambique na Região de Búzi, a cerca de $50 \mathrm{~km}$ da cidade da Beira. A destilaria produz 10,000 litros por dia, de etanol para bebidas e aplicações farmacêuticas usando melados como uma matéria prima.

\subsubsection{Biodiesel}

O biodiesel é uma mistura de ésteres metílicos de ácidos graxos produzidos por transesterificação de óleos vegetal ou gordura animal com álcoois de cadeia curta, geralmente o metano. Isso torna o biodiesel compatível para utilização em motores à diesel (MATAVEL; CHAVES, 2015; NETO et al., 2000). As espécies oleaginosas usadas para produzir biodiesel no País são: a semente de rícino, jatropha curcas, girassol, palma africana, amendoim, gergelim, coco, algodão, sebo ${ }^{3}$ bovino, gorduras suína e de frango, rejeitos de óleos usados nas frituras e óleos não adequados à alimentação animal.

Suas propriedades físicas são semelhantes às do diesel derivado do petróleo, porém, o biodiesel possui a grande vantagem socioambiental, por ser de fonte renovável, atóxico e biodegradável. Também pode ser utilizado como uma mistura, em qualquer proporção, com o diesel de petróleo sem que haja a necessidade de grandes ajustes no motor.

Para além das características técnicas (tabela 2), enquanto combustível, o biodiesel necessita das seguintes características: alta pureza, a reação de transesterificação deve ser completa, sem traços de glicerina, catalisador ou de álcool excedente (NETO et al., 2000).

\footnotetext{
${ }^{3}$ Sebo são gorduras animais que se apresentam sólidas na temperatura ambiente, dada a elevada concentração de ácidos graxos saturados, principalmente o esteárico.
} 
Tabela 2. Propriedades complementares atribuídas ao biodiesel em comparação ao óleo diesel

\begin{tabular}{c|l} 
Características & \multicolumn{1}{c}{$\begin{array}{c}\text { comercial. } \\
\text { Propriedades complementares }\end{array}$} \\
\hline $\begin{array}{c}\text { Características } \\
\text { químicas apropriadas }\end{array}$ & $\begin{array}{l}\text { Livre de enxofre e compostos aromáticos, alto número de cetanos, ponto de } \\
\text { combustão apropriado, excelente lubricidade, não tóxico e biodegradável. }\end{array}$ \\
\hline $\begin{array}{c}\text { Ambientalmente } \\
\text { benéfico }\end{array}$ & $\begin{array}{l}\text { Nível de toxicidade compatível ao sal ordinário, com diluição tão rápida quanto a } \\
\text { do açúcar (Departamento de Agricultura dos Estados Unidos). }\end{array}$ \\
\hline $\begin{array}{c}\text { Menos poluente } \\
\text { competitivo }\end{array}$ & $\begin{array}{l}\text { Reduz sensivelmente as emissões de }(i) \text { fumaça, (ii) monóxido de carbono, (c) } \\
\text { óxidos sulfúricos e (d) hidrocarbonetos policíclicos aromáticos. }\end{array}$ \\
\hline $\begin{array}{c}\text { Eeduz aquecimento } \\
\text { global }\end{array}$ & $\begin{array}{l}\text { O gás carbônico liberado é absorvido pelas oleaginosas durante o crescimento, o } \\
\text { sem a exigência da instalação de uma infraestrutura ou política de treinamento }\end{array}$ \\
\hline $\begin{array}{c}\text { Economicamente } \\
\text { atraente }\end{array}$ & $\begin{array}{l}\text { Permite a valorização de subprodutos de atividades agroindustriais, aumento na } \\
\text { arrecadação regional de impostos, aumento da fixação do homem no campo e de } \\
\text { investimentos complementares em atividades rurais. }\end{array}$ \\
\hline $\begin{array}{c}\text { Regionalização } \\
\text { gequenas e médias plantas para produção de biodiesel podem ser plantadas em } \\
\text { diferentes regióes do país, desfrutando-se da disponibilidade da matéria prima. }\end{array}$
\end{tabular}

Fonte: Adaptado de (Carvalho, Bortolini, \& Barcellos, 2014; Neto et al., 2000).

\subsubsection{Cogeração na indústria de papel}

A cogeração de energia se traduz na geração simultânea de duas ou mais utilidades (calor e energia eletromecânica), a partir de uma mesma fonte energética. Isto pode resultar nos benefícios: (i) econômico, através da redução de custos de combustíveis, quando comparada à produção das utilidades em separado, e (ii) ambientais, com a redução de emissões de poluentes decorrentes da queima de combustíveis (PEREIRA; NETO, 2011).

$\mathrm{Na}$ indústria de produção de pasta de papel e celulose são utilizados os materiais residuais do processo de cozedura da madeira designados licores negros ${ }^{4}$ que são queimados em caldeiras de recuperação que produzem vapor para utilização como fonte de energia térmica para o processo (ciclo de Rankine) e geração de energia elétrica. O licor negro é formado dentro do digestor no processo de polpação e queimado na caldeira de recuperação para cogeração de energia e a recuperação do licor branco. O processo de cogeração é eficiente e competitivo. O País apresenta um potencial de cogeração de 280 MW (ALER, 2017; GUEIFÃO et al., 2013).

\footnotetext{
${ }^{4} \mathrm{O}$ licor negro é um subproduto oriundo do processo de polpação da indústria de celulose e papel, formado por $60 \%$ de matéria orgânica (lignina e ácidos carboxílicos) e de $40 \%$ de matéria inorgânica $\left(\mathrm{NaOH}, \mathrm{Na}_{2} \mathrm{~S}_{2} \mathrm{Na}_{2} \mathrm{CO}_{3}\right.$, $\mathrm{Na}_{2} \mathrm{SO}_{4}, \mathrm{Na}_{2} \mathrm{~S}_{2} \mathrm{O}_{3}$ e $\mathrm{NaCl}$ )) em base seca.
} 


\section{MÉTODO}

Para alcance dos objetivos pretendidos usou-se os métodos bibliográfico, desk research e indutivo. O método bibliográfico foi utilizado na contextualização do setor de bioenergia em Moçambique. O embasamento teórico baseou-se na leitura de livros, artigos, dissertações e teses, sem delimitação temporal e espacial das publicações.

Para análise de dados secundários foi utilizado desk research, o que possibilitou o levantamento e a análise de informação na Atlas de Energias Renováveis, em relatórios técnicos das empresas ligadas a área e na legislação específica vigente em Moçambique. A análise da tecnologia usada em cada forma de biomassa usada em Moçambique foi possível pela correlação entre a quantidade de energia produzida e o tipo de aplicação.

A abordagem indutiva foi empregue na observação e análise particular, a partir das políticas nacionais e a utilização das fontes de biomassa, à conclusão geral sobre o estágio atual do uso e geração de bioenergias em Moçambique e as questões de sustentabilidade energética, definidas no $7^{\circ}$ objetivo de desenvolvimento sustentável da ONU (ONU, 2015).

\section{RESULTADOS E ANÁLISES}

\subsection{Política e legislação aplicadas a energia biomassa em Moçambique}

Moçambique é um País localizado no Sudeste do continente africano, situado entre as coordenadas $10^{\circ} 27^{\prime}$ e $26^{\circ} 56^{\prime}$ de latitude Sul e entre $30^{\circ} 12^{\prime}$ e $40^{\circ} 51^{\prime}$ de longitude Leste. Com uma superfície de $799.380 \mathrm{~km}^{2}$, a população estimada em 28,7 milhões, em 2017 (tabela 1) e uma densidade populacional média de 36 habitantes por $\mathrm{km}^{2}$.

A gestão dos recursos de biomassa usados para geração de energia está dividida entre os Ministérios da Terra, Ambiente e Desenvolvimento Rural (MITADER); da Agricultura e Segurança Alimentar (MASA); da Indústria e Comercio (MIC); do Trabalho, Emprego e Segurança Social (MITESS); e suas representações provinciais e distritais.

Moçambique é signatário dos seguintes acordos sobre a gestão de recursos naturais:

- A Convenção das ONU sobre a Biodiversidade, ratificada pela resolução 2/94, de 24 de agosto;

- Protocolo de Kyoto de 1997, ratificado pela resolução n. ${ }^{\circ}$ 10/2004, de 28 de julho;

- Agenda 21 aprovada na Conferência das Nações Unidas sobre o Ambiente e Desenvolvimento;

- e o Plano compreensivo de desenvolvimento da agricultura Africana, assinado em 2011.

Localmente, existem alguns instrumentos essenciais para a exploração sustentável dos recursos de biomassa, a destacar: Lei de terras, lei 19/97 de 1 de outubro (MOÇAMBIQUE, 
1997a); Lei do ambiente, lei 20/97, de 1 de outubro (MOÇAMBIQUE, 1997b); Política da energia, resolução $n^{\circ}$ 5/98 de 3 de março (MOÇAMBIQUE, 1998); Leis de florestas e fauna bravia, lei 10/99 de 7 de julho e lei no 12/2002 de 7 de julho (MOÇAMBIQUE, 1999, 2002); Política e estratégia de biocombustíveis (PEB), resolução $\mathrm{n}^{\circ}$ 22/2009 de 21 de maio (MOÇAMBIQUE, 2009a); Política de desenvolvimento de energias novas e renováveis, resolução n 62/2009 de 14 de outubro (MOÇAMBIQUE, 2009b); Comissão interministerial de biocombustíveis (CIB), decreto presidencial nº 7/20011, de 26 de julho (MOÇAMBIQUE, 2011a); e Regulamento de biocombustíveis e suas misturas com os combustíveis fósseis (RBMCF), decreto 58/2011, de 11 de novembro (MOÇAMBIQUE, 2011b);

No artigo 15 da Lei de florestas e fauna bravia, $n^{\circ}$ 12/2002 de 7 de julho, fica definido um dos marcos que determina a exploração dos recursos com fins energéticos. $\mathrm{O}$ artigo estabelece que as comunidades locais poderão, em qualquer época do ano, extrair os recursos florestais necessários ao seu consumo próprio, isentos de pagamento de taxa de exploração florestal (MOÇAMBIQUE, 2002, ponto 1). Porém, estes produtos só poderão circular dentro do Posto Administrativo em que a comunidade está inserida (MOÇAMBIQUE, 2002, ponto 2).

Ainda, no artigo 24 da mesma lei determina que "Não é permitida a utilização do produto principal de espécies florestais produtoras de madeira preciosa, de $1^{\mathrm{a}}, 2^{\mathrm{a}}$ e $3^{\mathrm{a}}$ classes, para a produção de lenha e carvão vegetal, bem como a utilização de espécies florestais raras, protegidas ou com valor histórico, sociocultural” (MOÇAMBIQUE, 2002).

Um dos maiores desafios na produção de biomassa florestal prende-se pela:

- Bioenergia versus segurança alimentar: as políticas em vigor não deixam claro a divisão entre culturas bioenergéticas e alimentares, e as respetivas áreas de cultivo. Face à isto, é necessário a definição de políticas e regulamentos, capazes de promover a utilização de matérias-primas, sem representar ameaças para a segurança alimentar, envolvendo a população rural na cadeia de produção, que ao mesmo tempo, atraia investimentos nacionais e internacionais no setor.

- Processo de aquisição de terra: Em Moçambique, a Terra é propriedade do Estado, não podendo ser vendida ou, por qualquer outra forma, alienada, hipotecada ou penhorada. Existe apenas o Direito de uso e aproveitamento da Terra, que pode ser adquirido por pessoas singulares ou coletivas e pelas comunidades locais (MOÇAMBIQUE, 1997a). O processo de acesso à terra, é considerado como uma das principais dificuldades no estabelecimento de investimentos e acesso ao mercado de negócios no País.

As matérias-primas selecionadas na PEB para a produção de etanol foram à cana-deaçúcar e sorgo açucarado da China. E para a produção de biodiesel foram o pinhão-manso e coco. A PEB promove a pesquisa de iniciativas e tecnologias inovadoras que favoreçam o estabelecimento de pequenas e médias empresas na produção de bioenergias e não pró́be o uso de outras matérias-primas (culturas e óleos) (MOÇAMBIQUE, 2009a). 
O RBMCF define as normas de gestão de todas atividades na cadeia de produção biocombustíveis e suas misturas (MOÇAMBIQUE, 2011b). As exportações só são permitidas depois de asseguradas às quantidades mínimas de mistura de combustíveis fósseis com biocombustíveis para o consumo no País (MOÇAMBIQUE, 2011a, art. 12).

\subsection{Produção e utilização dos recursos de biomassas em Moçambique}

Moçambique tem diferentes recursos de biomassas, desde biomassa florestal com um potencial de $1006 \mathrm{MW}$, as açucareiras com $823 \mathrm{MW}$, a indústria de pasta de papel com 280 MW e os RSU com 63 MW. Há ainda explorações florestais em Lichinga, o palmar e indústria do arroz em Quelimane, as 4 açucareiras existentes e ainda o novo aterro de Maputo, onde se identificaram $128 \mathrm{MW}$ para potenciais projetos (ALER, 2017; GUEIFÃO et al., 2013).

A disponibilidade de recursos bioenergéticos justifica a necessidade de se realizar pesquisas e adoção de estratégias para superar o atual déficit energético no País, visto que, as tecnologias para a geração deste tipo de energia alternativa, limpa e renovável, são ainda pouco conhecidas no seio das nossas comunidades (MONJANE \& BARROS, 2015, p. 7).

Com a crescente produção de biomassas no País, observa-se uma tendência de aprimoramento e difusão das tecnologias das biomassas nas comunidades. Este processo pode ser considerado um resgate, pois na pré-história a energia era provinda da biomassa (lenha e carvão), cujo seu potencial energético é elevado, podendo ser queimando em temperaturas bem mais elevada e por mais tempo (NASCIMENTO \& LOPES, 2018, p. 10).

A questão da produção de energia através de recursos de biomassa pode estar associada a um contexto e desejo de desenvolvimento de um novo modelo de sociedade, que contemple o fortalecimento do agronegócio, da agricultura familiar e desenvolvimento econômico, por meio da criação de empregos e geração de receita, controle social, descentralização da produção e consumo, redução do êxodo rural e da dependência externa de energia, em função da sua disponibilidade local (MORET et al., 2006, p. 2).

Porém, o uso energético da biomassa em Moçambique apresenta diversos aspectos condicionantes. Antes, temos que referir a questão da concorrência entre as bioenergias e alimentos, resultante do inadequado planejamento agrícola e de utilização do solo.

Outro aspecto a considerar é a promoção do desenvolvimento de biomassas através da divulgação de informação sobre a sua capacidade para uso energético e de potenciais benefícios socioambientais e econômicos. Na visão de Brand et al. (2014) deve-se ainda verificar se haverá ganhos sociais e econômicos em função da geração de emprego e renda a partir da criação e desenvolvimento do mercado de resíduos. 
Souza et al. (2015) fundamentam que um dos aspectos econômicos de maior relevância é a energia produzida de forma descentralizada a partir da biomassa, o que implica um uso potencial maior e mais disseminado de energia, já que representa um insumo de baixo custo para o seu produtor. Outros aspectos socioeconômicos meritórios são a redução da importação de combustíveis fósseis, a geração de emprego em toda cadeia produtiva e a disseminação de tecnologias energéticas nas zonas rurais.

O uso de biocombustíveis na substituição dos combustíveis fósseis na matriz energética nacional é urgente e oportuno sob perspectivas ambiental, econômico e social. Esses vetores, segundo Souza et al. (2015) representam uma contribuição aos esforços internacional para redução de emissão de gases de efeito estufa (GEE) que geram o aquecimento global. Mas a sustentabilidade requer maior responsabilidade, austeridade e equidade nos padrões mundiais de produção, de consumo e do uso da energia.

\subsection{Tecnologias energéticas dos biocombustíveis em Moçambique}

As biomassas apresentam uma solução energética para um número considerável dos Moçambicanos. 95\% dos agregados familiares dependem de biomassa lenhosa como fonte de energia para cozinhar e aquecer alimentos, aquecer o ambiente caseiro e iluminação.

Moçambique detém extensivos recursos de biomassa, com $43 \%$ do País coberta por florestas. $80 \%$ da energia usada no País são na forma de biomassa tradicional. O crescimento da população, a urbanização e as expansões agroculturais geram uma maior pressão sobre os recursos de biomassa, levando ao estado crítico, em algumas regiões com danos irreversíveis causados a diversos níveis. Ao perder a cobertura florestal, o País corre o risco de perder um grande recurso doméstico e a oferta de energia renovável de baixo custo (VISSER, 2012: p. 1).

Atualmente surge a preocupação ambiental, não pela quantidade de GEE emitido, mas pelo desflorestamento contínuo de grandes áreas rurais e os problemas de erosão. Como resposta, o crescente aumento do preço e escassez de recursos, nos centros urbanos, há substituição destes, pelo gás de uso doméstico e etanol, e nas zonas rurais, há introdução de fogões eficientes de carvão para uso doméstico e industrial. Porém, são apontados como essenciais e estratégicos, os seguintes elementos:

- Incentivo no uso de biomassa renovável sem desflorestamento direto: uma prática comum no meio rural onde as populações, sem interferir diretamente no decurso dos processos naturais, usam o material lenhoso seco como fonte de energia (MONJANE; BARROS, 2015);

- Uso de Etanol: uma alternativa explorada com sucesso no País, em substituição ao carvão vegetal, num programa introduzido e liderado pela Clean Star Moçambique desde 2012 (MONJANE; BARROS, 2015; MOTA; MONTEIRO, 2013);

- Produção de fogões de alta eficiência energética: tecnologia de fogões melhorados ndzilo, à etanol (Fig. 4A) e mbaula, à carvão (Fig. 4B) adequados para as atividades domésticas, para 
além de terem eficiência energética, economia, mais limpos e "amigos" do ambiente (AQUINO et al., 2018; MONJANE; BARROS, 2015);

- Produção de biogás e biodiesel: processo bioquímico de produção biogás envolve a transformação anaeróbica da biomassa e compreende as fases de: hidrólise, acidogênese, acetogênese e metanogênese. Em função da temperatura do processo, o tratamento dos resíduos pode ser agrupado em três tipos: (i) biometanação termofílica que ocorre a uma temperatura entre $45-60^{\circ} \mathrm{C}$; (ii) mesofílica que ocorre entre os $20-45^{\circ} \mathrm{C}$ e; (iiii) a digestão anaeróbia crofílica que ocorre abaixo dos $20^{\circ} \mathrm{C}$ (MONJANE; BARROS, 2015; MOTA; MONTEIRO, 2013).

Figura 4 - Fogão melhorado: Nzilo, à etanol (A) e Mbaula, à carvão vegetal (B).

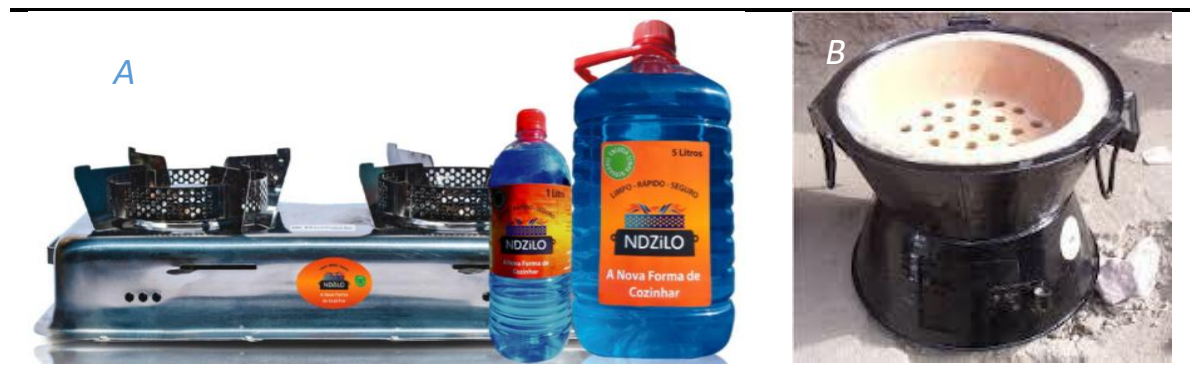

Fonte: Extraídos do site: https://www.cleancookingalliance.org/technology-and-fuels/ > acesso no dia 04/03/2020.

\subsection{Aspectos sustentáveis dos recursos energéticos de biomassas}

A energia da biomassa contribui de forma significativa para o balanço energético. Nos Países em vias de desenvolvimento, a maior parte da biomassa é utilizada de forma tradicional para aquecimento e preparação de alimentos, sendo a sua utilização, em grande parte, insustentável (MONJANE; BARROS, 2015). Este fato, gera impactos negativos, através de desflorestamento, erosão, perda da biodiversidade, perda de nutrientes dos solos e a poluição, tanto do meio ambiente como no interior da casa, sem chaminé.

A bioenergia moderna pode ser aplicada em pequena escala para uso local, em mini redes ou unidades autônomas, e na produção e comoditização em grande escala. A produção sustentável de bioenergia promove usos mais eficientes da biomassa sólida, reduzindo o desflorestamento e a degradação da terra associada à agricultura de subsistência. Por essas razões, os produtores agroindustriais e as comunidades locais estão empenhados a desenvolver tecnologias de alto rendimento e sustentáveis, com vista a rentabilizar as culturas energéticas, potencializar o agronegócio e promover o desenvolvimento socioeconômico nas áreas rurais.

O uso de óleo residual como matéria-prima alternativa às oleaginosas para obter biodiesel, têm atraído a atenção de vários produtores de biodiesel a nível internacional, devido ao seu potencial de oferta, baixo custo de aquisição e elevado potencial energético (OLIVEIRA, 2004; WANG, 2013). Além disso, o óleo resídual não requer grandes extensões de terra, 
insumos agrícolas e água para ser produzido. Pelo contrário, é descartado diariamente de forma errada em pias e vasos sanitários gerando um impacto negativo para os sistemas de esgoto, ou depositados diretamente nos cursos de água e no solo.

O descarte de óleos residuais nos cursos de água prejudica as espécies aquáticas pois, pela diferença de densidade entre o óleo e a água, o óleo cria uma camada que impede a entrada de luz, reduz a interface ar-água, dificulta as trocas gasosas e, consequentemente diminui a concentração de oxigênio na água. E o despejo de óleos residuais no solo, causa obstrução dos interstícios do solo, dificultando a drenagem das águas, tornando o ambiente propício para enchentes (FREITAS; BARATA; NETO, 2010). Como alternativa nacional, urge a necessidade de se adotar políticas e programas que promovem e estimulam a reciclagem do óleo residual, para produção do biodiesel, eliminando-se algumas ameaças socioambientais e economicas, para além de contribuir para o desenvolvimento sustentável.

Souza et al. (2015, p. 4) divide os aspetos sustentáveis das biomassas em:

- Segurança energética: garantir energia para os países em via de desenvolvimento significa afastar-se de formas ineficientes de bioenergia tradicional e seu impacto negativo sobre o meio ambiente e a saúde humana;

- Segurança alimentar: a bioenergia moderna pode ajudar a melhorar a segurança alimentar por meio da otimização da produtividade da terra e do manejo agrícola, criando sinergias em toda a cadeia de abastecimento de alimentos e de biomassas;

- Segurança ambiental e climática: a bioenergia pode desempenhar o papel crucial na mitigação dos problemas socioambientais atuais. Mas deve-se considerar a eficiência e a sustentabilidade dos sistemas bioenergéticos e o impacto das mudanças no uso da terra nas emissões de GEE, segurança alimentar, recursos hídricos, conservação da biodiversidade e meios de subsistência.

\section{CONSIDERAÇÕES FINAIS}

Conforme discutido, a utilização de biomassa lenhosa está presente no estilo de vida dos moçambicanos. Este fato está associado com a disponibilidade, volatidade, baixo valor econômico e questões de sustentabilidade socioambiental e econômicas comprovadas, tornando-a a principal fonte de energia para uso doméstico. É sustentável a relação entre a produção de alimento - geração de bioenergia - preservação do meio ambiente.

A produção de bioenergia moderna em Moçambique está numa fase embrionária. $\mathrm{O}$ biodiesel e biogás são fontes promissoras de bioenergia, de longo prazo, com potencial para minimizar os impactos ambientais e as preocupações de segurança, representadas pela dependência atual dos combustíveis fósseis. Porém, para alcançar esse patamar torna-se indispensável investimentos e pesquisas voltadas a realidade nacional, com vista a adequar o 
uso de tecnologias eficientes, que promovem serviços de maior qualidade, reduzem a quantidade da biomassa transformada em energia e contribuem na sustentabilidade energética.

Parte da adequação deve ser feita na legislação específica sobre bioenergias e criar-se incentivos fiscais na redução de tributos sobre a importação e exportação de tecnologias de produção sustentável de bioenergias, voltada às zonas rurais e áreas suburbanas.

Perante a atual crise na matriz energética mundial, a questão de sustentabilidade bioenergética desempenha um fator importante no desenvolvimento socioambiental e econômico do País. A inclusão do biogás e biodiesel na matriz energética nacional pode resolver, em simultâneo, os problemas energéticos e de gestão sustentável de RSU e RSI.

\section{REFERÊNCIAS}

ALER. Energias renováveis em Moçambique: Relatório Nacional do ponto de situação.

2. ed. Maputo: Associação Lusófona de Energias Renováveis, 2017.

AQUINO, A. et al. Notas sobre a Floresta em Moçambique. Maputo: Grupo Banco Mundial e Sweden Sverige, 2018.

BRAND, M. A. et al. Produção de biomassa para geração de energia em povoamento de Pinus taeda L. com diferentes idades. Redalc.org, v. 38, n. 3, p. 353-360, 2014.

BROUWER, R.; FALCAO, M. P. Wood fuel consumption in Maputo, Mozambique. Biomass and Bioenergy, v. 27, p. 233- 245., 2004.

CARDONA, C. A.; QUINTERO, J. A.; PAZ, I. C. Production of bioethanol from sugarcane bagasse: Status and perspectives. Bioresource Technology, v.101, n.13, p.4754-4766, 2010.

CARVALHO, A. P. C. DE; FERREIRA, R. L. A utilização de biocombustíveis como alternativa sustentáveis na matriz energética Brasileira. Caderno Meio Ambiente e Sustentabilidade, v. 5, n. 3, p. 139-157, 2014.

CARVALHO, N. L.; BORTOLINI, J. G.; BARCELLOS, A. L. Biocombustíveis: uma opção para o desenvolvimento sustentável. Revista GEDECON, v. Epecial, p. 32-50, 2014.

DIB, F. H. Produção de biodiesel a partir de óleo residual reciclado e realização de testes comparativos com outros tipos de biodiesel e proporções de mistura em um motogerador. Dissertação de Mestrado em Engenharia Mecânica, Universidade Estadual Paulista "Júlio de Mesquita Filho", Ilha Solteira, SP, 2010.

ECUSEB. Estrateégia de coservação e uso sustentável de energia da biomassa. Para o período 2014-2025. Maputo: Biofund, 2013.

FERREIRA, A. L. D. Culturas energéticas : produção de biomassa e bioenergia. Dissertação de Mestrado em Engenharia Mecânica, Univ. de Coimbra, Coimbra, 2015.

FREITAS, C. F. DE; BARATA, R. A. DA R.; NETO, L. DE S. M. Utilização do óleo de cozinha usado como fonte alternativa na produção de energia renovável, buscando 
reduzir os impactos ambientais. XXX Encontro Nacional de Engenharia de Produção. Anais...São Carlos, SP: Enegep, 2010

GOLDEMBERG, J. Biomassa e energia. Quimica Nova, v. 32, n. 3, p. 582-587, 2009.

GUEIFÃO, C. et al. Atlas das energias renováveis de Moçambique: Recursos e projectos para produção de electricidade. 1. ed. Maputo: Gesto-Energia, S.A., 2013.

LANGA, J. M. DO R. C.; SOUZA, J. G. DE; HESPANHOL, R. A. DE M. A produção de alternativas agroenergéticas e a questão da terra em Moçambique: a província de Manica. Campo-Território: revista de geografia agrária, v. 8, n. 15, p. 1-31, 2013.

MARAFON, A. C. et al. Uso da Biomassa para a Geração de Energia. 1. ed. Aracaju, SE: Embrapa Tabuleiros Costeiros, 2016.

MATAVEL, N.; CHAVES, G. Caracterização do Setor de Biodiesel no Moçambique. Espacios, v. 36, n. 3, p. 13-21, 2015.

MOÇAMBIQUE. Lei de Terras, Lei no 19/97 de 1 de outubro. Bolentim da República de Moçambique, Maputo, 1997a.

MOÇAMBIQUE. Lei 20/1997, de 1 de outubro. Lei do Ambiente. Bolentim da República de Moçambique, Maputo, $1997 \mathrm{~b}$.

MOÇAMBIQUE. Resolução no $5 / 98$ de 3 de março. Politica energética. Bolentim da República de Moçambique, Maputo, 1998.

MOÇAMBIQUE. Lei no 10/99 de 7 de junho, Lei de Floresta e Fauna Bravia. Bolentim da República de Moçambique, Maputo, 1999.

MOÇAMBIQUE. Decreto no 12/2002 de 6 de junho. Lei de Florestas e Fauna Bravia. Bolentim da República de Moçambique, Maputo, 2002.

MOÇAMBIQUE. Resolução n⿳2 22/2009 de 21 de maio. Política e estratégia de biocombustíveis. Bolentim da República de Moçambique, Maputo, 2009a.

MOÇAMBIQUE. Resolução 62/2009, de 14 de outubro. Política de Desenvolvimento de Energias Novas e Renováveis. Bolentim da República de Moçambique, Maputo, 2009b.

MOÇAMBIQUE. Decreto Presidencial n. ${ }^{\circ}$ 7/2011 de 26 de julho. Criação da Comissão Interministerial de Biocombustíveis (CIB). Bolentim da República de Moçambique, Maputo, 2011a.

MOÇAMBIQUE. Decreto $n .{ }^{\circ}$ 58/2011 de 11 de novembro. Regulamento de Biocombustíveis e suas Misturas com combustíveis fósseis. Bolentim da República de Moçambique, Maputo, 2011b.

MONJANE, A. A. R.; BARROS, J. A. P. DE. Potencialidades bioenergéticas em Moçambique. Revista Eletrônica de Energia, v. 5, n. 1, p. 5-12, 2015.

MORET, A.; RODRIGUES, D.; ORTIZ, L. Critérios e indicadores de sustentabilidade para bioenergia. Fórum Brasileiro de ONGs e Movimentos Sociais. Anais...São Paulo-SP: FBOMS, 2006 
MOTA, C. J. A.; MONTEIRO, R. S. Química e sustentabilidade: novas fronteiras em biocombustíveis. Quimica Nova, v. 36, n. 10, p. 1483-1490, 2013.

NASCIMENTO, F. N.; LOPES, M. B. Biomassa: fonte sustentável de energia. Revista Científica Semana, v. 1, p. 1-13, 2018.

NETO, P. R. C. et al. Produção de biodiesel alternativo ao óleo diesel através da transesterificação de óleo de soja usado em frituras. Quimica Nova, v23 n.4 p.531-537, 2000

NUBE, T. G. et al. Impactos Socioeconômicos das Plantações Florestais no Niassa, Moçambique. Floresta e Ambiente, v. 23, n. 1, p. 52-60, 2016.

OLIVEIRA, L. B. Potencial de aproveitamento energético de lixo e de biodiesel de insumos residuais no Brasil. Tese de Doutorado em Ciências em Planejamento Energático, Universidade Federal do Rio de Janeiro - UFRJ, Rio de Janeiro, RJ, 2004.

ONU. A Agenda 2030 para o Desenvolvimento Sustentável. Disponível em: <http://www.agenda2030.org.br/sobre/>. Acesso em: 19 abr. 2020.

PEREIRA, W. D.; NETO, J. L. Uso de biomassa na geração de energia elétrica na industria de celulose. Congresso Brasileiro de Resíduos Orgânicos. Anais...Vitória, ES: Fibria, 2011

PITOL-FILHO, L. Aplicações sustentáveis de biomassa: novas perspectivas. Revista da Unifebe (Online), v. 9, p. 100-109, 2011.

PROTÁSIO, T. DE P. et al. Torrefação e carbonização de briquetes de resíduos do processamento dos grãos de café. Revista Brasileira de Engenharia Agrícola e Ambiental, v. 16, p. 1252-1258, 2012.

RAPOSO, F. L. Q. et al. Aproveitamento de biomassa resultante da serragem e painagem da madeira em Moçambique. 35th SENAFOR. Anais...Porto Alegre, RS: 2015

SITOE, A.; SALOMÃO, A.; WERTZ-KANOUNNIKOFF, S. O contexto de REDD+ em Moçambique: Causas, actores e instituições. Bogor Barat: Publicação Ocasional 76, 2012.

SOUZA, V. H. A. DE et al. Aspectos sustentáveis da biomassa como recurso energético. Revista Augustus, v. 20, n. 40, p. 105-123, 2015a.

SOUZA, G. M. et al. Bioenergia e Sustentabilidade. Resumo para Políticas Públicas. Paris: Scope, 2015b.

VAZ, A. K. et al. Green Investments In Mozambique. Maputo: BoM - AFD, 2011.

VISSER, I. DE. Biomass Energy Strategy (BEST) Mozambique. Energy for development, p. $1-2,2012$.

WANG, L. Z. Life Cycle Assessment of Biodiesel Production from Waste Cooking Oil in Western Australia. 3rd International Conference on Chemical, Ecology and Environmental Sciences. Anais...Bali - Indonesia: ICCEES'2013, 2013 